
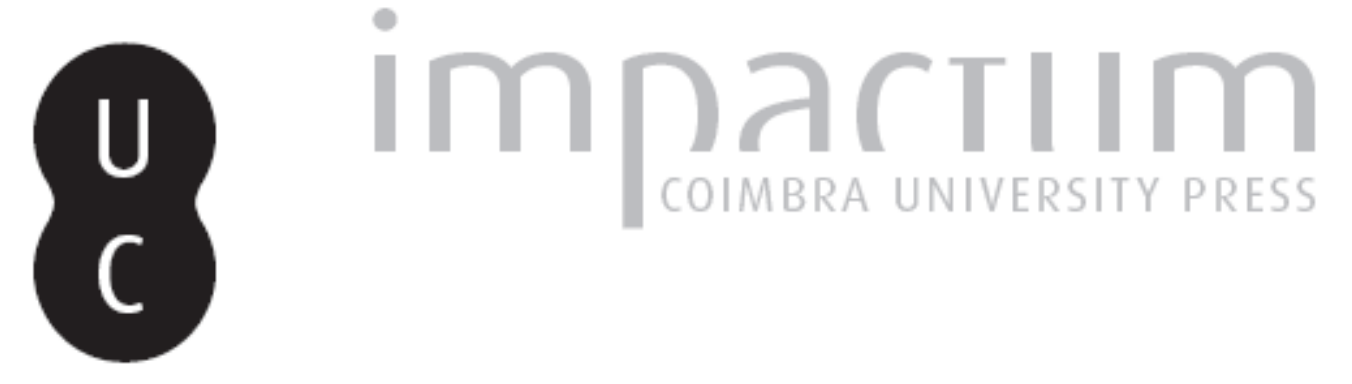

\title{
A diáspora africana numa trajetória geográfica, territorial e libertadora: da África ao Brasil: a liberdade em Redenção
}

Autor(es): $\quad$ Bastos, Ana Paula Pinto

Publicado por: Imprensa da Universidade de Coimbra

URL persistente:

URI:http://hdl.handle.net/10316.2/38317

DOI:

DOI:http://dx.doi.org/10.14195/0871-1623_34_7

Accessed : $\quad$ 26-Apr-2023 14:54:28

A navegação consulta e descarregamento dos títulos inseridos nas Bibliotecas Digitais UC Digitalis, UC Pombalina e UC Impactum, pressupõem a aceitação plena e sem reservas dos Termos e Condições de Uso destas Bibliotecas Digitais, disponíveis em https://digitalis.uc.pt/pt-pt/termos.

Conforme exposto nos referidos Termos e Condições de Uso, o descarregamento de títulos de acesso restrito requer uma licença válida de autorização devendo o utilizador aceder ao(s) documento(s) a partir de um endereço de IP da instituição detentora da supramencionada licença.

Ao utilizador é apenas permitido o descarregamento para uso pessoal, pelo que o emprego do(s) título(s) descarregado(s) para outro fim, designadamente comercial, carece de autorização do respetivo autor ou editor da obra.

Na medida em que todas as obras da UC Digitalis se encontram protegidas pelo Código do Direito de Autor e Direitos Conexos e demais legislação aplicável, toda a cópia, parcial ou total, deste documento, nos casos em que é legalmente admitida, deverá conter ou fazer-se acompanhar por este aviso.

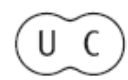




\title{
A diáspora africana numa trajetória geográfica, territorial e libertadora: da África ao Brasil (a liberdade em Redenção) The African diaspora in geographic trajectory, territorial and liberation: from Africa to Brazil (freedom in Redemption)
}

\author{
Ana Paula Pinto Bastos
}

Universidade de Coimbra. paulaappb@gmail.com

\section{Resumo:}

A análise refere-se a um estudo de uma das trajetórias geográficas das imigrações africanas que chamamos de involuntárias e está embasado em autores como Rogério Haesbaert, João Luís Fernandes, Rafael Sanzio entre outros geógrafos e historiadores que realizam estudos sobre o tema "território" e "diásporas". Alexandre Marcussi ${ }^{1}$ e Gilberto Freyre através de discussões sobre pluralidade étnica e pluralidade cultural brasileira envolveram estudos na temática "território", não apenas como definido e delimitado a partir de relações de poder, mas como resultado da ação de um grupoo social. A escravatura deixou uma memória que se inscreve na paisagem cultural brasileira polissêmica, com uma diversidade que culminou na diferença de povos, línguas, cultos religiosos, hábitos alimentares e até na musicalidade. Ou senão uma pluralidade de territórios com múltiplas paisagens geográficas. Todavia, a distribuição dos conteúdos a serem analisados está seccionada em: conceito geográfico de diáspora; territorialização da diáspora; reterritorialização e alguns aspectos da libertação em Redenção/Ceará/Brasil.

Palavras-Chave: Diáspora. Território. Paisagem. Desterritorialização.

\section{Abstract:}

The analysis refers to a study of the geographical trajectories of African immigrations we call involuntary and is based on authors such as Roger Haesbaert, João Luís Fernandes, Raphael Sanzio, among others geographers and historians who conduct research on "territory" and "diaspora". Alexandre Marcussi and Gilberto Freyre conducted studies on ethnic diversity and cultural plurality Brazilian studies involving the theme "territory," not only as defined and delimited from power relations, but as a result of the action of a social group. Slavery left a memory which is in Brazilian cultural landscape polysemic, with a diversity that culminated in the difference of peoples, languages, religious services, eating habits and even in musicality. Or else a plurality of regions with multiple geographic landscapes. However, the distribution of content to be analyzed is split into: geographical concept of diaspora; territorial diaspora; repossession and some aspects of liberation in Redemption/Brazil.

Keywords: Diaspora. Territory. Landscape. Deterritorialization.

\section{Introdução}

0 ensaio refere-se a um estudo analítico, de uma das trajetórias geográficas das imigrações africanas que podemos ou devemos chamá-las involuntárias. Dessa forma, temos o intuito de contribuir na ampliação das informações sobre as referências territoriais de deslocamentos entre África e Brasil, entretanto é preciso, que se diga que é através de estudos cartográficos mais detalhados, onde se encontrarão de maneira mais específica os aspectos historiográficos para a formação do território brasileiro. Outrossim, acrescento que o estudo não pretende aprofundar e nem explorar o aspecto carto- gráfico e sim a trajetória espacial e geográfica dos deslocamentos entre África e Brasil.

A metodologia escolhida seguiu um estudo realizado através de uma revisão bibliográfica embasada em autores como: Rogério Haesbart, João Luís Fernandes, Yves Barel, Rafael Sanzio, e outros geógrafos e historiadores que realizam estudos sobre o tema "território". Outras referências deram suporte e que estão evidenciadas nos estudos anteriores sobre registros da liberdade dos escravos em Redenção/Ceará/Brasil.

A paisagem que surge no contexto advindo do processo que envolve novas configurações com a chegada dos negros da África, apresenta-se com 
determinadas "nuances territoriais" ou características derivadas de um sistema econômico e comercial imposto no Brasil com nomenclaturas diversas como "comércio de escravos"; "comércio escravista"; tráfico de africanos, enfim. A partir de então, novas habitações são criadas para dar sequência ao tipo de comércio, numa lógica capital de atendimento fiel da colônia (Brasil) para à metrópole (Portugal). 0 homem que modifica a paisagem pode ser visto como "territorial" ou "territorializador" como disse Yves Barel, entretanto na visão de (HAESBAERT, 2004a), o que existe é um movimento complexo de territorialização, que inclui a vivência concomitante de diversos territórios, configurando uma multiterritorialidade. Esse novos espaços criados no território, eram o que hoje chamamos de Pernambuco, Bahia e Rio de Janeiro. Tais estados brasileiros absorveram muito dos valores e culturas africanas numa magnitude nacional, transcendendo para diversos povos, vilas e cidades. É preciso lembrar da essência da colonização portuguesa no Brasil, da sociedade agrária e escravocrata que se formou, de como o índio, o negro e português contribuíram para este Brasil que conhecemos. O autor Freyre (1933), conseguiu apresentar em sua obra, o cotidiano do Brasil Rural do início do século XIX, período no qual o país passava por transformaçõe e a sociedade presenciava uma centralização administrativa que alterava o lugar dos grupos de poder local e regional, acompanhados da urbanização e da reestruturação da família e de suas moradias.

O Brasil registra as maiores estatísticas de importação forçada de contingentes populacionais africanos do século XVI ao XIX. Devido a sua duração e amplitude, nos limitamos a uma escala temporal referente a um período que corresponde a um intervalo entre os séculos XVII e XVIII. De acordo com estudos anteriores, nesse período, se constituíram as mais significativas e duradouras extensões territoriais das rotas do tráfico negreiro, que correspondem as Costas da Mina e de Angola. É nesse período que vão ocorrer os maiores volumes de povos africanos transportados para o território do Brasil. De acordo com estudos realizados pela Unesco, registrados respectivamente em 1994 e 2010, numa coleção com 8 volumes, intitulada "Coleção História Geral da África da UNESCO", a região que marcava a saída dos povos negros da África ou o início das rotas, abrangia o interior das baías do Benim e Biafra, (atualmente Nigéria e Camarões) na costa ocidental africana, indo na direção à cidade do Rio de Janeiro no Brasil, de onde saíram aproximadamente $40 \%$ do total dos escravos enviados para as Américas (UNESCO, 1994). É preciso acrescentar que essa linha geográfica de deslocamento específico, privilegia a compreensão das formas particulares de organização dos escravos oriundos da Baía do Benim que integram o grupo que os portugueses convencionaram chamar de "pretos minas".

Merece destaque, a longevidade dessa rota, sendo que vinha desde a África até o Rio de Janeiro como aconteceu no século XVIII com passagens entre outras partes do Brasil como Pernambuco e Bahia. A
Figura 1 a seguir, demonstra as linhas de tráfico para os estados mencionados. ${ }^{1}$

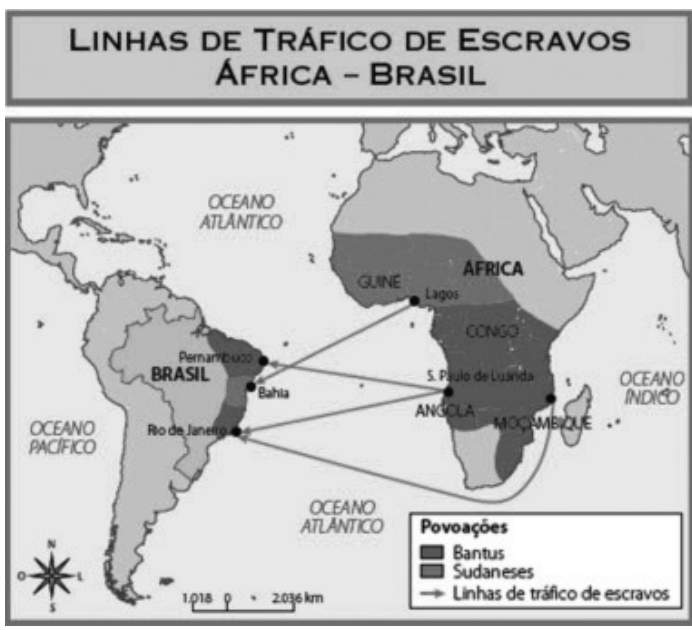

Figura 1

Linhas de tráfico de escravos África-Brasil

Fonte: https://www.google.com.br/s253BT, acesso em 01.12.2014.

A escravatura deixou uma memória que se inscreve na paisagem cultural brasileira, uma paisagem polissêmica com uma diversidade que culminou na diferença de povos, línguas, cultos religiosos, hábitos alimentares e até na musicalidade. Ou senão uma pluralidade de territórios com múltiplas paisagens geográficas. Alguns exemplos práticos podem ser apresentados aqui como a cidade de Palmares (no Estado de Alagoas), originada do Quilombo dos Palmares, região de grande resistência com aglomeração de negros que fugiam dos engenhos e que ali se fixavam compartilhando seus cultos, ritos, práticas artesanais, alimentícias e de danças, etc., e o convívio ali praticado culminou numa absorção da cultura vivenciada entre os povos que ali viviam. Outro exemplo que merece destaque é a cidade baiana de São Francisco do Conde (localizada na Região Metropolitana de Salvador-Capital da Bahia), área considerada pelo IBGE-Instituto Brasileiro de Geografia e Estatística (2010), um local que possui a maior quantidade de negros descendentes dos Povos Malês no Brasil. E um terceiro exemplo que merece destaque é a valorização da ancestralidade, que conforme o Departamento de Educação/Núcleo de História e Memória da Universidade Federal do Ceará, o NACE-Núcleo de Africanidades Cearenses, são realizados estudos sobre ancestralidade, cosmovisão com uma metodologia de estudos sobre africanidades através da Pretagogia, na qual se busca a igualdade entre povos para a confirmação dos efeitos da escravatura na paisagem e história do Brasil. A Pretagogia fundamenta-se em várias contribuições teóricas, a

Disponível:https://www.google.com.br/search?q=mapa+do+Brasil+com+as+principais+rotas+de+escravos\&espv=2\&tbm=isch\&imgil=wapaSeLIZqgM\%253A\%253BT. Acesso em 01.12.2014. 
partir da crítica sócio-antropológica realizada por Kabengele Munanga (2011) ${ }^{2}$.

Para alguns arquitetos como Leo Name (2010), o conceito de "paisagem" não é exclusivo da geografia, no qual cita Meneses (2002: 29), que aponta que a paisagem é tema "extremamente amplo, cheio de veredas que se multiplicam, alternativas que não se excluem" e destaca como problema, o fato de "paisagem" ser palavra extremamente polissêmica, pois o mesmo considera que é utilizada como mero termo de sentido comum.

No que se refere à manipulação da paisagem, tanto em regimes totalitários como em regimes democráticos, o Estado tem tido papel de relevo, construindo territórios pedagógicos de veiculação de valores, mobilização de massas e criação de narrativas comuns que filiem a comunidade a correntes políticas ou agregações colectivas como o Estado- Nação (FERNANDES, 2009). A paisagem emerge conforme ocorre a conquista do território que segue uma dinâmica própria. Os conceitos serão abordados por se tratar de aspectos fundamentais e interligados sobre a temática proposta, porque compreendemos que para o estudo proposto, precisamos recorrer aos fundamentos.

Todavia, a distribuição dos conteúdos a serem analisados está seccionada em: Conceito geográfico de Diáspora; Territorialização da diáspora; Desterritorialização e Reterritorialização e Alguns aspectos da libertação em Redenção/Ceará/Brasil.

Portanto, a análise poderá reunir uma composição de materiais, para uma compreensão de processos ocorridos numa dinâmica geográfica de parte das rotas que culminaram numa determinada territorialidade de espaços do Brasil colonial caracterizado por poderes políticos e econômicos. Traz ainda, um padrão histórico e geográfico de leitura dos fatos arbitrários e opressores relativos aos povos que estão inclusos nesta saga "escravatória".

\section{Conceito geográfico de diáspora}

Para nos situarmos geograficamente é preciso uma observação gráfica dos locais que mostram como se configurou a rota do estudo específico visualizando os continentes: Europa, África e América do Sul. Dessa forma, podemos verificar as rotas específicas no que se refere a São Jorge da Mina. A figura apresentada na sequência nos mostra de maneira ilustrativa, as distâncias entre os continentes e a precariedade das embarcações utilizadas no transporte dos povos. A concentração do olhar na cidade do Rio de Janeiro (um dos mais importantes portos atlânticos), se mostra como uma estratégia inovadora para estudar esse grupo em profundidade, assim como perceber a complexidade das redes comerciais aí envolvidas. (UNESCO, 2004). Não só Rio de Janeiro está em

\footnotetext{
2 MUNANGA, Kabengele - Lutas contínuas concretizam mudanças sociais e raciais. In: http://www2.fpa.org.br/sites/default/files/Kabengele_ Muna
}

evidência, mas também, Recife e Salvador aparecem como pontos estratégicos na costa brasileira.

Na visão de Soares (2000: 2), "surge uma nova geografia que incorpora a Guiné ao universo cognoscitivo europeu. Mais que qualquer outra parte do mundo, a Guiné é o lugar dos tempos modernos. É na exploração de suas terras e de seus mares que os portugueses constroem a modernidade ibérica" (SOARES, 2000).

A autora reforça a ideia de que praticamente toda a literatura sobre tráfico de escravos e escravidão africana no Mudo Novo, se refere, com frequência aos africanos como "escravos de Guiné". Sabe-se, que a maior quantidade de escravos, vinha dessa região, mas mesmo assim a autora reporta-se a indagação de outro historiador, Charles R. Boxer (1967), mas de que tratam efetivamente os historiadores - assim com os escritos de época nos quais eles se baseiam - quando se referem à "Guiné" e aos "escravos de Guiné".

O movimento histórico das grandes navegações na concepção de Anjos (2013: 263), deve ser entendido como uma consequência direta do processo geográfico de dominação territorial, desenvolvido, amadurecido e implementado pelo continente europeu. O horizonte geográfico das terras emersas vai ser ampliado de forma significativa pelos novos encontros de culturas, identidades e territorialidades. Como resultado, o mapa do mundo vai ser profundamente modificado nos séculos XV, XVI, XVII, XVIII E $X I X$, sobretudo pelos novos territórios a ele incorporado e as "novas" fronteiras constituídas e impostas. Este período da história dos seres humanos vai se caracterizar por uma nova fase de relações entre estes e a natureza.

De acordo com publicação do autor Anjos (2008), "no século XVII o tráfico vai ser dinamizado na Costa de Angola, transportando povos africanos para a Bahia, Pernambuco, Alagoas, Rio de Janeiro, São Paulo e regiões do centro-sul do Brasil, e na Costa da Mina, com fluxos para as províncias do Grão-Pará, Maranhão e o território atual do Rio Grande do Norte. A antiga Costa da Mina compreende atualmente os territórios dos seguintes países: Costa do Marfim, Libéria, Burquina Fase, Mali, Níger, Congo, Gana, Togo, Benin, Nigéria e Camarões. A conhecida Costa de Angola corresponde atualmente aos seguintes países: Angola, Gabão, República Democrática do Congo e Guiné Equatorial. Nos séculos XVII e XVIII, vão se constituir as mais importantes e duradouras extensões territoriais das rotas do tráfico negreiro: as Costas da Mina e de Angola" (ANJOS, 2008)

Ainda para Anjos (2011), a Costa de Angola, no século XVII, vai se caracterizar pela intensidade do tráfico, fato que vai incrementar a entrada de grande contingente de povos Bantus na região açucareira do Brasil, expandindo-se para o sudeste (Rio de Janeiro, São Paulo, Minas Gerais) e Goiás, no centro da "Colônia". O tráfico se transferiu temporariamente para o Golfo da Guiné (Costa da Mina) e povos Jeje-Mina vão ser transportados para territórios já conhecidos como o Maranhão e o Grão-Pará, assim 
como, uma expansão no nordeste na direção do atual Estado do Rio Grande do Norte. No século XVIII, estão os registros das maiores quantidades de seres humanos do continente africano na condição de escravizados e transportados para o Brasil. Distintos grupos de línguas Bantus, como os Congos, Cabindas e Angolas, principalmente, vão se expandir pelo território brasileiro em formação, com registros em quase todos os portos da costa brasileira. Da Costa da Guiné foram trazidos para a Bahia os Nagôs-lorubás e os Hauçás (populações de sudaneses islamizados ou não) (ANJOS, 2011). No século XIX, temos registros da Abolição da escravidão no Brasil, mas a dinâmica demográfica de novas adaptações ao espaço, agora utilizado pelos ex-escravos, após a sua liberdade propriamente dita, irá incorrer em processos diversos, com rupturas culturais, geográficas e históricas na absorção da nova vida.

Na perspectiva conceitual, o termo "diáspora" tem origem na Grécia e significa dispersão de povos, por motivos políticos ou religiosos. Este conceito surgiu pela primeira vez devido ao movimento de dispersão dos judeus no mundo antigo. Um conceito mais aprofundado merece abordagens antropológica, sociológica e histórica. Para Stuart Hall, o conceito fundamenta-se na construção de "uma fronteira de exclusão e depende da construção de um "Outro" e de uma oposição rígida entre o dentro e o fora" (HALL, 2008: 32). É importante mencionarmos também outra publicação significativa sobre a temática, é o livro: "At home in Diáspora - Black International Writing", de Wend Walters, onde ela afirma ser "espaço global uma teia de abrangência mundial que se deve tanto pelo continente original quanto por qualquer lugar do mundo que seus filhos possam ter sido levados pelas infortunas forças da história" (Walters 2005, p. vii). Tal definição apresenta um sentido claro do "maternal da terra" que perde seus filhos em detrimento do domínio de outros ou de outras terras. Seria então a diáspora "uma ausência do lar"?

Numa visão através de crendice dentro da historiografia africana, estudiosos como a professora Zélia Amador de Deus (Cedenpa-Centro de Estudo e Defesa do Negro do Pará-Brasil), utiliza a metáfora de ananse, a aranha que foi capaz de tecer uma grande teia e conseguir o baú de histórias das mãos de Kwame e permitir que tivessem histórias. Ananse, a deusa, acompanhou seus filhos espalhados pelo mundo. 0 mito de Ananse, originário da cultura dos povos Fanthi-Ashanti, da região do Benin, na África Ocidental, se espalhou e se renovou e se renova em diversos lugares das Américas. Ananse e suas histórias, acompanharam seus filhos na afro-diáspora. Os africanos que atravessaram para as Américas, na condição de escravos, foram destituídos de tudo, inclusive de sua humanidade ao serem transformados em mercadorias, "coisificados". Neles, o colonizador imprimiu o código dos europeus e deles se apossou, na condição de proprietário, senhor.

Para alguns geógrafos, o conceito geográfico de diáspora tem haver com a referência de dispersão de uma população e das suas matrizes culturais e tecnológicas. É preciso que se diga que apesar de uma referência histórica de matriz africana existente no Brasil, os processos para a compreensão das dinâmicas sociais, espaciais e econômicas podem ser facilitados através da ciência geográfica. Na concepção de Anjos (2013: 262), a geografia é a ciência do território e este componente fundamental, a terra, o terreiro num sentido amplo, continua sendo o melhor instrumento de observação do que aconteceu, porque apresenta as marcas da historicidade espacial; do que está acontecendo, isto é, tem registrado os agentes que atuam na configuração geográfica atual e o que pode acontecer, ou seja, é possível capturar as linhas de forças da dinâmica territorial e apontar as possibilidades da estrutura do espaço no futuro próximo.

A geografia é uma disciplina fundamental para estudos da composição étnica que apresenta uma heterogeneidade ímpar na contribuição socioeconômica e espacial. Dessa maneira, a compreensão do tráfico atlântico pode nos trazer aspectos da elucidação das condições de aprisionamento, tipo de transporte e como foram distribuídos em seus cativeiros. 0 trajeto da viagem não podia ser pior, a rota era traçada pelos europeus que determinavam todos os processos e trâmites da viagem que era realizada através das caravelas (embarcações da época), na qual os povos eram desprovidos de qualquer tratamento humano. O poeta brasileiro chamado de "poeta dos escravos", Castro Alves retratou a embarcação como "Navio Negreiro" referenciado nas estrofes a seguir...,

"Desce do espaço imenso, ó águia do oceano!

Desce mais... inda mais... não pode olhar humano

Como o teu mergulhar no brigue voador!

Mas que vejo eu aí... Que quadro d'amarguras!

É canto funeral! ... Que tétricas figuras! ...

Que cena infame e vil... Meu Deus! Meu

Deus! Que horror!

Era um sonho dantesco... o tombadilho Que das luzernas avermelha o brilho.

Em sangue a se banhar.

Tinir de ferros... estalar de açoite...

Legiões de homens negros como a noite, Horrendos a dançar..."

(CASTRO ALVES, 1868)

No entanto, o poema foi concluído quase vinte anos depois, da promulgação da Lei Eusébio de Queirós, que proibiu o tráfico de escravos na data de (04) quatro de setembro de 1850 . A proibição não foi tão obedecida, ou seja, não vingou, o que levou o citado poeta a se empenhar na denúncia da miséria a que eram submetidos os africanos, no então cruel percurso oceânico. Devemos lembrar que, segundo informações de pesquisadores, aproximadamente menos da metade dos escravos embarcados nesses navios "negreiros" conseguiam completar a viagem ainda com vida.

Entretanto, além de mudanças econômicas, o tráfico provocou interações significativas entre povos 
da África, das Américas, Europa e o mundo árabe-mulçumano, transformando as culturas, conhecimentos, crenças e comportamentos. O que alguns chamam de "interculturalidade". Entretanto, uma vez instalados em quaisquer dos continentes, por mais que as tradições fossem aniquiladas, pela cultura predominante da época, os descendentes de africanos davam início a um processo de invenção, criação e re-criação da memória cultural para preservação dos laços mínimos de identidade, cooperação e solidariedade. Nesta rede de interação, como afirma Zélia Amador de Deus (2008), as múltiplas culturas africanas que se espalharam pelo mundo, preservaram marcas visíveis dos traços africanos. Marcas que exerceram importância fundamental para que esses africanos e seus descendentes realizassem sua reconstrução pessoal e coletiva.

\section{Territorialização da diáspora}

A territorialização pode ser entendida como as múltiplas formas de construção/apropriação concreta ou simbólica do espaço social, assim, partir do materialismo histórico pode-se entender que a primeira "grande desterritorialização capitalista" liga-se a sua própria origem, ao seu "ponto de partida", a acumulação primitiva de capital, que distingue separadamente, produtor e meios de produção. Trata-se assim, da expropriação das populações do campo de sua base fundiária e sua transformação em trabalhador livre em busca de trabalho nas cidades. “A dissociação entre trabalhador e 'controle' (domínio e apropriação) dos meios de produção (da terra para cultivar à fábrica ou aos instrumentos para produzir) é a grande desterritorialização, imprescindível, de qualquer modo, à construção do capitalismo" (HAESBAERT, 2004: 175).

\section{Desterritorialização e Reterritorialização}

Onde existir desterritorialização, há também reterritorialização, pois no sentido, de que alguns povos chegam à outra terra, que não seja a sua, caracteriza-se assim, "territorialidade sem território" como diria Haesbart (2004), ou seja, a assimilação de novos espaços ou a formação destes através dos que ali habitam com seus costumes, histórias e hábitos. Porém, do ponto de vista historiográfico das diásporas africanas, a reterritorialização aconteceu de uma forma dolorosa e trágica, até mesmo por causa das imposições inseridas em suas vidas. Não sabemos nem se tinham "vidas", pois eram tratados como seres inferiores, sem a mínima autonomia sobre si.

Os negros da África, originários da escravidão chegam aos novos territórios brasileiros, vindos de tribos distintas e ambientes diferentes, como já mencionamos anteriormente, os quais precisaram se organizar entre si, numa "interculturalidade", propriamente dita, com dificuldades de inserção, sobretudo na língua, na alimentação, cultos religiosos e outros. Essa relação entre as culturas trouxe para os povos da África, escravizados na terra estranha "Brasil" uma nova forma de viver e de "ser" e ao longo dos anos formaram o que chamamos hoje de povos "afro-descendentes". Na reflexão filosófica do autor André (2012: 501), a interculturalidade: “(...) nas suas dimensões e acentuando a consciência da sua incontornável natureza que radica na sua forma peculiar de configuração de mundividências e comportamentos e na fonte de sentido que confere à existência cotidiana, na relação dos homens entre si, dos homens com o mundo e dos homens com o mistério que os ultrapassaou com o sagrado que silenciosamente os inspira num convite à contemplação e ao enraizamento no fundo indivisível de uma transcendência acolhida na interioridade do humanum." (ANDRÉ, 2012: 501)

Pensar em interculturaalidade significa buscar a integração das culturas presentes, porém em um país de dimensões territoriais tão grandes, é natural a existência da diversidade, pluralidade ou multiculturalidade entre os povos. A diversidade étnica e cultural que compõe a sociedade brasileira se compreende através de suas relações marcadas por desigualdades socioeconômicas. O contexto gerado trouxe transformações com dimensões multiculturais, transculturais e interculturais. No que se refere a multiculturalidade, num conceito popular, podemos dizer que é a união de diversas culturas, ou seja riquezas culturais observadas e praticadas em um só país com povos de diferentes ancestralidades.

Ao longo do processo de dispersão africana, podemos identificar a construção de territórios através da mobilidade das migrações involuntárias e/ou de livre espontânea vontade, provavelmente essa categoria última pode ter ocorrido por motivos diversos. Nessa perspectiva de análise pretendemos caracterizar a diáspora que está inserida no intervalo dos séculos XVII e XVIII. Em estudos de Anjos (2011), não era apenas as riquezas da África que interessavam a Europa Moderna, mas os seres humanos também eram necessários aos colonizadores para o cultivo e exploração das minas. Caracterizando-se assim, um novo período de escravidão humana associada ao acúmulo de capitais, organizado num sistema político e econômico que permitiu o desenvolvimento de uma grande empresa comercial, possibilitando a expansão do capitalismo, onde esse tráfico demográfico forçado do continente africano para o americano pode ter sido uma das maiores atividades comerciais da época. Os povos foram retirados de suas origens, trazendo sua bagagem cultural para serem incorporados a novas realidades da nova terra. Poderíamos então afirmar que tais povos já estavam desterritorializados? Ou, estariam forçados e/ou condenados a uma reterritorialização? Neste contexto, Appadurai (2004), Ortiz (1994) e Ianni (1992) in Fernandes (2008), associam a desterritorialização à mobilidade transnacional de fenômenos e atores que escapam à regulação nacional, como por exemplo, as diásporas e as empresas multinacionais. Para Haesbart (2004), a desterritorialização seria uma espécie de mito, incapaz de reconhecer o caráter imanente da (mul- 
ti)territorialização na vida dos indivíduos e dos grupos sociais.

Entretanto, nas considerações de Barel (1986), geograficamente não há desterritorialização, pelo simples fato de que o homem é um "animal territorial". Porém, no contexto dos povos africanos, a reterritorialização que chamamos aqui de "diaspórica”, aconteceu seguindo outra dinâmica. Tal processo obedecia a uma lógica perversa, a escravagista, na qual esses povos foram literalmente "arrancados" de suas vidas, rotinas e de seus territórios para serem vendidos em mercados ou entrepostos comerciais do Brasil. Quando nos reportamos às palavras de Haesbaert (2007), afirmamos que ocorre aí a territorialidade sem território, ou seja, predominam as relações de poder, se evidenciando o domínio aos seres destituídos de qualquer coisa, chamados por Mílton Santos, de "atores hegemonizados" (SANTOS et al., 2000: 12). O que significa dizer, que os povos absorveram a hegemonia dominante (o poder hegemônico indissolúvel evidente na época) e ainda perderam seus territórios devido às circunstâncias, onde passaram a viver em espaços indefinidos e arbitrários, como propõem Bonnemaison e Cambrezy (1996), "subalternizados".

Ainda sob o ponto de vista geográfico, a desterritorialização será um processo (muitas vezes, violento e quase sempre involuntário) de privação de espaço. Esta corresponde a um condicionamento territorial a uma perda de controlo e domínio das territorialidades pessoais e/ou coletivas à redução evidente das acessibilidades aos lugares económicos e simbólicos aos recursos, à habitação, a outros locais que constituem eixos estruturantes da identidade e da territorialidade de cada grupo ou indivíduo (FERNANDES, 2013). Todavia, partindo da ideia que existem territórios com maior ou menor rigidez de seus limites, variando de acordo com as práticas espaciais que determinado grupo social desenvolve, ou com o papel que este mesmo sustenta no tecido social, Di Méo (2001: 8), esclarece: “(...) todos os indivíduos que hoje formam os grupos sociais, também possuem uma competência territorial (ao mesmo tempo que social). Sem dúvida, nem todos possuem o mesmo status, nem todos detém o mesmo poder de operar e criar territórios. Entre os principais detentores dessa capacidade estão os representantes do poder político institucional, os líderes da economia e os diferentes líderes (culturais, religiosos, ideológicos) da opinião. Em segundo plano, os indivíduos que produzem e reproduzem o cotidiano, que também, são importantes promotores do território".

Desse modo, o território é o resultado da ação de legitimidade de um grupo social. Não significa dizer que o território é mais genuíno ou verdadeiro que outro, mas que a intensidade com que se afirma ou se busca legitimar as bases territoriais traduzem, de certa maneira, a influência que determinada sociedade possui. Assim sendo, as bases que contribuem para a formação de um território, reportam-se à noção de identidade de um grupo social.
Alguns aspetos da libertação em Redenção/Ceará/ Brasil

O significado da palavra "Redenção" no sentido bíblico se refere à liberdade, livramento. Alguns fatos importantes antecederam a abolição propriamente dita. 0 estado do Ceará interrompeu o desembarque de africanos escravizados nos portos cearenses (Porto do Mucuripe), comandado por Francisco José do Nascimento, em 1881, como um fato marcante da história oficial do estado. O líder desse movimento resistente de jangadeiros ficou conhecido como "Dragão do Mar", que deu nome ao maior centro cultural da capital.

Segundo historiadores cearenses, o município de Redenção foi o primeiro município do Maciço a emancipar-se de Baturité com o nome de Vila de Acarape, em 1868. No mesmo dia da criação da Vila, foi promulgada uma lei autorizando o Presidente da Província do Ceará a despender, anualmente, a quantia de quinze mil réis com a libertação de escravos de preferência do sexo feminino. Esse fato parece ter influído no ânimo dos habitantes da vila que passaram a lutar contra o jugo escravista. De acordo com o IBGE, região dos sopés do Maciço de Baturité e ao redor das margens do Rio Acarape/Rio Pacoti era habitada por diversas etnias como os Potyguara, Jenipapo, Kanyndé, Choró e Quesito, recebeu a partir do século XVII diversas expedições militares e religiosas. Em 1882 é criada a "Sociedade Redentora Acarapense". Em 1 de janeiro de 1883, chegavam à então Vila Acarape, abolicionistas como Liberato Barroso, Antônio Tibúrcio, Justiniano de Serpa, José do Patrocínio e João Cordeiro, com a finalidade de assistirem a alforria de 116 escravos do lugarejo. A partir daquele ato, em frente à igreja matriz local, não haveria mais escravos ali, ganhando a vila o nome de Redenção, pioneira em libertar seus escravos no País. 0 mapa a seguir (Figura 2) apresenta a macrorregião de Baturité que envolve os municípios do entorno de Redenção. Este foi elevado à condição de cidade com a denominação de Redenção, pela lei provincial $n^{\circ} 2167$, de 17-08-1889.

Conforme informação na página da Unilab ${ }^{3}$, a cidade recebeu os cognomes de "Berço das Auroras" e "Rosa da Liberdade". Em 1889 a então vila da Acarape recebeu foros de cidade e foi denominada de Redenção, em homenagem ao grande evento abolicionista.

De acordo com informações da Sociedade Libertadora Artística de Acarape e a Sociedade Redentora Acarapense, Fundadas em 1882, as duas assumir a vanguarda do movimento abolicionista que culminou com uma proclamação "NESTA TERRA NÃO HÁ MAIS ESCRAVA". Em janeiro de 1883 um telegrama foi enviado ao Imperador D. Pedro II comunicando a extinção da escravatura Vila de Acarape. No ano de 1889 a vila de Acarape, denominada de "Rosal da Liberdade" e "Berços das Auroras" foi elevada a cidade com o nome de Redenção, numa homenagem ao evento abolicionista.

3 http://www.unilab.edu.br/wp-content/uploads/2013/01/Hist\%C3\% B3ria-de-Redenc\%C3\%A3o.pdf/acesso01.12.2014. 


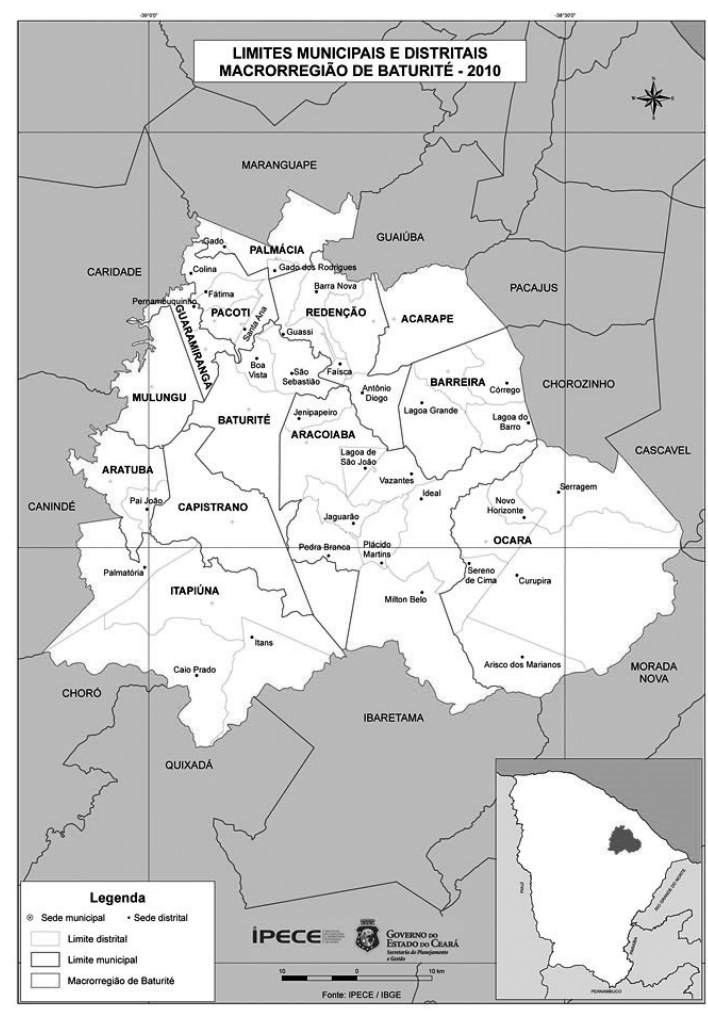

Figura 2

Limites municipais e distritais: Macrorregião de Baturité - 2010. Fonte: IPECE-Instituto de Pesquisa e Estratégia Econômica do Ceará, 2007.

\section{Conclusões e Recomendações}

A independência política do município de Redenção/Acarape e sua história trouxeram influências que acarretaram mudanças do ponto de vista espacial, paisagístico, cultural e turístico do local. Foi também trazido à tona informações da Sociedade Libertadora Artística de Acarape e a Sociedade Redentora Acarapense, Fundadas em 1882, nas quais assumiram a vanguarda do movimento abolicionista que culminou com uma proclamação "NESTA TERRA NÃO HÁ MAIS ESCRAVA”. Em janeiro de 1883 um telegrama foi enviado ao Imperador D. Pedro II comunicando a extinção da escravatura Vila de Acarape. No ano de 1889 a vila de Acarape, denominada de "Rosal da Liberdade" e "Berços das Auroras" foi elevada a cidade com o nome de Redenção, numa homenagem ao evento abolicionista.

É preciso que se conheça mais sobre os aspectos da História e da Geografia do país, para que a nação tenha conhecimento de povos que são nossos ancestrais. Nas Escolas de Educação Básica, a partir do ano de 2003, a nova Lei 6.639/2003 que inclui o ensino de história e cultura afro-brasileira ressalta a importância da cultura negra na formação da sociedade brasileira. A referida lei obriga a realização nas escolas brasileiras, dentro da disciplina de His- tória, estudos que contemplem a história da África. Dessa forma, aspectos como: dimensões culturais, espaciais e paisagísticas foram surgindo gradativamente com as novas realidades da colonização, advindas da Diáspora Africana e que gerou uma realidade socioeconômica voltada para a mão de obra escrava e exportadora.

Na perspetiva da Geografia como ciência que estuda o Território, devemos observar como se configuram os novos espaços. A criação de engenhos aglutinou pessoas, como a casa grande, as lavouras, enfim, um cotidiano, apesar de doloroso para os povos escravizados. Outro aspecto que merece ser mencionado é o surgimento dos quilombos, construídos pelos negros que fugiam de suas realidades tétricas para um convívio mais próximo de sua cultura de maneira coletiva. Nesses espaços se formavam aldeias que refugiavam escravos e ficavam escondidas nas matas, em lugares inacessíveis, onde os mesmos poderiam levar uma vida livre. Eram os quilombos, que segundo informações históricas, o termo tem origem angolana. Um dos quilombos mais conhecidos era o de "Palmares", com sua localização no estado de Alagoas, na Região Nordeste do Brasil.

Portanto, acreditando ser de grande significância neste trabalho uma abordagem sobre a Diáspora e territorialidades da "escravidão", é primordial trazermos à tona outra temática: "o preconceito racial", embora possam surgir novas territorialidades, que se apresentam com configurações espaciais e de tempos modernos específicos do último século, lamentavelmente ainda existe não só no Brasil, mas em diversas nações. Muitos afrodescendentes ainda são tratados ou vistos de maneira preconceituosa por parte da população local. Assim sendo, acrescento a necessidade de incentivar o processo educacional para a construção ou reconstrução de novos conceitos geográficos, paisagísticos, históricos e sociais em abordagens que observem o real sobre as rotas africanas. A geografia pode colaborar para a compreensão do mundo contemporâneo, "ciência do território" é, portanto, uma disciplina fundamental na formação da cidadania do povo brasileiro, que apresenta uma heterogeneidade singular na sua composição étnica, socioeconômica e na distribuição espacial (ANJOS, 2011).

\section{Referências Bibliográficas}

ANJOS, R. S. A. (2011) - Territorialidade Quilombola: fotos \& mapas / Quilombola territoriality: photos \& maps. Brasília. Mapas Editora \& Consultoria., 124 p.

ANJOS, R.S. A. (2012) - Geopolítica da diáspora África América - Brasil. Séculos XV - XVI - XVII - XVIII - XIX. Cartografia para educação. Brasília, Mapas Editora \& Consultoria.

APPADURAI, A. (2004) - Dimensões culturais da globalização. Lisboa, Teorema. 
BAREL, Y. ( 1986) - "Le social et ses territoires". In: AURIAC, F. e BRUNET, R. (orgs.) - Espaces, Jeux, et Engeux. Paris, Fayard e Fondation Diderot.

BONNEMAISON, J. e CAMBREZY, L. (1996) - Le lien territorial: entre frontières et identités. Paris, Géographies et Cultures (Le Territoire) n. 20. Paris, L'Harmattan CNRS.

DEUS, Z. A. (2008) - Os herdeiros de ananse: movimento negro, ações afirmativas, cotas para negros. Tese de doutorado da Universidade Federal do Pará-UFPA.

DI MÉO, G. (2001) - Geographie sociale et territoires. Paris: Nathan. 320 p.

FERNANDES, J. L. (2008) - “A desterritorialização como fator de insegurança e crise social no mundo contemporâneo". In: I Jornadas Internacionais de Estudos sobre Questões Sociais. AGIR-Associação para a Investigação e Desenvolvimento Sócio-Cultural, Póvoa de Varzim, pp. 423-447.

FERNANDES, J. L. (2011) - "Geografia, territorialidades difusas e insegurança: a fragmentação, as dinâmicas, de desterritorialização e as novas dimensões do espaço geográfico num mundo complexo e instável". Geopolítica - Revista do Centro Português de Geopolítica. Aveiro.

FERNANDES, J. L. (2009) - "Cityscapes - simbolos, dinamicas e apropriações da paisagem cultura urbana". Máthesis, $n^{\circ} 18$, pp. 195-214. Centro de Estudos de Geografia e Ordenamento do Território (CEGOT) Universidade de Coimbra.

FREYRE, G. (1933) - Casa Grande e Senzala. Formação da família brasileira sobr o regime de economia patriarcal. Maia e Schmidt, Rio de Janeiro.

HAESBART, R. (2004) - O mito da desterritorialização: do fim dos territórios à multiterritorialidade. Bertrand, Brasil. Rio de Janeiro.
HALL, Stuart. (2003) - Da diáspora: identidades e mediações culturais. Organização Liv. Sovik, Tradução Adelaine La Guarda Resende. Belo Horizonte: 410 p. ISBN 97885-7041-356-7 Editora UFMG.

IANNI, O. (1992) - A sociedade global. Civilização Brasileira. Rio de Janeiro.

MUNANGA, Kabengele (2011) - Lutas contínuas concretizam mudanças sociais. In: RIBEIRO, Matilde (Org.). Direitos humanos como direitos de todos, sem exceção. São Paulo, Ed. Fundação Perseu Abramo, p. 144.

ORTIZ, R. (1994) - Mundialização e cultura. Brasiliense, São Paulo.

SANTOS, M. et al. (2000) - O papel ativo da geografia: um manifesto. Florianópolis, XII Encontro Nacional de Geógrafos.

SOARES, Mariza de (2000) - "Descobrindo a Guiné no Brasil colonial". R /HGB, Rio de Janeiro, 16/(407), pp. 71 94.

WALTERS, Wendy (2005) - At home in diaspora: Black international writing. The University of Minnesota Press. 179 p. ISBN 0-8166-4492-6.

Páginas da web consultadas

http: / / unesdoc.unesco.org/images/0014/001465/146546por. pdf/acesso02.12.2014.

http://www.unilab.edu.br/wp-content/uploads/2013/01/ Hist \% C 3\%B 3ria-de-Redenc\%C3\%A3o.pdf/ acesso01.12.2014

http://www.e-net.com.br/seges/poesia.html/acesso/ acesso02.12.2014.

MUNANGA, Kabengele - Lutas contínuas concretizam mudanças sociais e raciais. In: http://www2.fpa.org.br/sites/ default/files/Kabengele_Munanga.pdf/acesso 03.12.2014. 